The forms themselves did later mention that the haemoglobin was falling, but the warning was condensed on the left side below the blood parameters at the bottom of the form. Asterisks were not used. By contrast, however, the status 'green' was in block capitals in open space on the opposite side of the page, drawing the reader's eye to it instantly. This patient has subsequently undergone investigation and treatment for anaemia.

This is another example of a false sense of security gained by relying upon CPMS monthly blood counts. Had they been routine local blood tests then medical staff would have, in my view, assessed each form more thoroughly, paying attention to more than one parameter - as opposed to the solitary concern about a fall in white cell count. The CPMS form needs to have a different layout so as to allow for other abnormalities to be drawn to the doctors' attention sooner.

R. H. Davies, Consultant Psychiatrist, Ymiddiriedolaeth Gig Bro Morgannwg NHS Trust, Glanrhyd Hospital, Bridgend, Mid Glamorgan CF31 4LN

\section{Driving in Somerset}

Sir: I agree that to deprive older people of transport could seriously inconvenience them (Psychiatric Bulletin, December 2000, 24, 469), however, the new General Medical Council guidelines Confidentiality; Protecting and Providing Information (2000) specifically states that "The Agency [DVLA] needs to know when driving licence holders have a condition which may now, or in the future, affect their safety as a driver.... If patients refuse to accept the diagnosis or the effect of the condition on their ability to drive, you can suggest that the patients seek a second opinion, and make appropriate arrangements for the patients to do so. You should advise patients not to drive until the second opinion has been obtained."

No, I do not want to alienate older people with mild cognitive impairment, but I do feel that we have a duty to the public in assessing and monitoring these people. They can, after all, have a driving assessment arranged through regional test centres if they feel they want to appeal against advice not to drive.

GENERAL MEDICAL COUNCIL (2000) Confidentiality; Protecting and Providing Information. London: GMC.

Stefan Kolowski, Specialist Registrar in Old Age Psychiatry, Rydon House, Cheddon Road, Taunton TA2 7AZ

\section{Urinary detection of olanzapine and its limitations}

Sir: Sander (Psychiatric Bulletin, January 2001, 25, 33) is correct in pointing out some of the limitations of urinary detection of olanzapine as a proxy for compliance, as previously described by myself (Coates, 1999, 2000). Currently, only a negative result shows non-compliance, whereas a positive result is open to various interpretations. I am presently studying two ways of potentially addressing these shortcomings, which may prove helpful.

First, I am investigating the quantification of the urinary levels of olanzapine, rather than just using a qualitative test. This should provide more of an indication of the actual compliance when levels are ascertained. Second, the measurement of urinary metabolites, either quantitatively or qualitatively, may lead to a more sophisticated approach in the future. In particular, $10-\mathrm{N}$-glucuronide is the most abundant metabolite but $4{ }^{\prime}-\mathrm{N}$-desmethylolanzapine is correlated to clearance (Callaghan et al, 1999) and this may give a better indication of a person's recent compliance.

Currently, however, non-detection of urinary olanzapine remains the best objective test of non-compliance and with these further developments it may prove to be even more valuable in clinical practice.

CALLAGHAN, J.T., BERGSTROM, R. F., PTAK, L. R., et al (1999) Olanzapine. Pharmacokinetic and pharmacodynamic profile. Clinical Pharmacokinetics, 37, 177-193.

COATES, J.W. (1999) Urinary detection of olanzapine - an aid to compliance. British Journal of Psychiatry, 175, 591-592.

- (2000) Urinary detection of olanzapine - an aid to compliance confirmed. Psychiatric Bulletin, 24, 316 .

John W. Coates, MB MRCPsych,

Consultant Psychiatrist, Mental Health Services, Rotherham General Hospital, Moorgate Road, Rotherham S60 2UD

\section{National Service Framework}

Sir: As Deahl et al (Psychiatric Bulletin, June 2000, 24, 207-210) recently pointed out, whether those considering committing suicide will use NHS Direct, and therefore lower the number of suicides and meet a standard of the National Service Framework (NSF) for Mental Health (Department of Health, 1999), is uncertain. How NHS Direct will be used by people for mental health related problems of any nature is also uncertain, even though there is an emphasis on its use for this client group in the NSF.
In order to work towards the implementation of the NSF we carried out a small pilot study in one NHS Direct site to learn more about how people with mental health related problems were using the service. For the period of 1 week we collected data on all mental health related calls to the site. This was done by asking nurses to complete data forms for every mental health call, and by looking at the presenting complaints of all other calls to pick up any that were obviously mental health related. We identified 33 mental health related calls during the week, which accounted for $2.6 \%$ of the workload. Given that nurse advisers did not complete a data collection form for every mental health call, and that the data on presenting complaints were unreliable, we were able to estimate that mental health is more likely to account for approximately $4 \%$ of NHS Direct's workload.

The 33 calls related to 24 callers, the majority of whom (67\%) were calling on their own behalf. Of these $24,37.5 \%$ presented with more than one problem, some of which were complex and time consuming for nurse advisers to deal with. Just over one-third of the calls were prioritised as either immediate or urgent, the same figure not urgent, and the majority (66\%) were referred to another service. This differed to all calls received during the study period where $57 \%$ were prioritised as not urgent and only $43 \%$ were referred onto another service.

The study demonstrated that NHS Direct is being used by people for their mental health problems and already performing one of the tasks in the NSF of enabling this client to contact another service. How well this task is being undertaken is something that needs to be monitored. Work is currently underway to evaluate the $f 1$ million investment the Government has given to ensuring NHS Direct can meet this task, and results will be available shortly.

DEPARTMENT OF HEALTH (1999) National Service Framework for Mental Health. Modern Standards and Service Models. London: Department of Health.

Fiona Payne, Senior Researcher, Lynda Jessopp, Project Manager, Guy's, King's and St Thomas' School of Medicine

\section{Personal psychotherapy, training and psychodrama}

Sir: I read with interest Chris Mace's views on the relevance of personal psychotherapy to training (Psychiatric Bulletin, January 2001, 25, 3-4). As a specialist registrar in general adult psychiatry, I have recently started psychodrama training as my special interest. When Moreno, the founder of psychodrama and philosophical antagonist 